Celal Bayar University Journal of Science

\title{
Synthesis of Aromatic Conjugated Main Chain Azobenzene Polymers and Their Properties
}

\author{
Zeynep Bilen ${ }^{1}$, Erhan Budak ${ }^{1}$, Mustafa Kemal Bayazit ${ }^{2,3}$ and Özdemir Özarslan ${ }^{1 *}$ \\ ${ }^{1}$ Department of Chemistry, Faculty of Art \& Sciences, Abant Izzet Baysal University,14280 Golkoy, Bolu, Turkey \\ ${ }^{2}$ Department of Chemical Engineering, University College London, Gower Street, London, WC1E 6BT, UK \\ ${ }^{3}$ SUNUM Nanotechnology Research and Application Centre, Sabanci University, 34956, Tuzla, Istanbul, Turkey \\ *ozarslan_o@ibu.edu.tr
}

Received: 23 July 2018

Accepted: 14 December 2019

DOI: $10.18466 /$ cbayarfbe.446974

\begin{abstract}
Azobenzene polymers have great potential and impact on fundamental and applied research. However little is known about their thermal stability and degradation behavior. Herein, nine conjugated main chain azobenzene polymers were synthesized using the nitroamine derivatives of some diphenylene compounds such as 4-amino-4'-nitrobiphenyl 1, 4-amino-4'-nitrobiphenyl ether 2 and 4-amino-4'nitrobiphenyl sulfide 3 , and comonomers triphenylamine A, $N$-methyldiphenyl amine B and triphenylphosphine $\mathrm{C}$ via a diazo coupling reaction. These heteroatom-containing polymers were characterized by $1 \mathrm{H}-$ and 31P-NMR, FTIR, UV-Vis and Raman spectroscopy. The thermal stability and degradation behavior of these polymers were studied by means of TGA technique. Electronic spectra of the polymers recorded in DMF showed two strong maxima at ca. 280 and $380 \mathrm{~nm}$. They were resistant to heat up to $270{ }^{\circ} \mathrm{C}$ and, produced $41-61 \%$ char under a nitrogen atmosphere at $800{ }^{\circ} \mathrm{C}$. UL 94 burning tests performed for TPU Ravathane ${ }^{\circledR}$ (TPE-U) with added azobenzene polymer revealed that these polymers could be used as an intumescent reactive flame retardant additive, particularly for polyurethanes and elastomers, due to their high char yield at relatively high temperatures (e.g $800{ }^{\circ} \mathrm{C}$ ). The carbonized materials were further characterized by XRD and SEM/EDX.
\end{abstract}

Keywords: Main chain azobenzene polymers; intumescent flame retardant additive; thermal stability; thermal degradation and carbonization.

\section{Introduction}

Polymer systems containing azobenzene moieties are known to have improved physical and chemical properties such as viscosity, photoresponsivitiy, refractive index, conductivity, nonlinear optical susceptibility, mechanical properties and polymer morphology [1]. Such changes enable azobenzene polymers to be used for various photonic applications including LEDs, edge-emitting lasers, optical fibre communications and optical storage [1]. Thus, considerable effort has been devoted to synthesizing both aromatic side-chain and main-chain azobenzene polymers [1]. A previous study revealed that the mobility of main-chain azobenzene polymers decreased due to the azobenzene groups in the polymer mainchain, however, the polymer backbone had enough flexibility for the alignment of the main chain [2]. The main-chain azo polymers have usually been investigated for the stability of photoinduced properties, liquid crystalline properties [3, 4] and third-order nonlinear optic properties $[5,6]$. The azobenzene containing conjugated polymers have also been used for manufacturing functional materials with unexpected optical, electrical and magnetic properties [1]. For example, conjugated main chain azo polymers synthesized by Timpu and co-workers showed real photoconductor properties between 350 and $600 \mathrm{~nm}$ [7]. Poly( $p$-phenylene), poly(phenylene-ethylene) and poly( $p$-phenylene-vinylene) have been synthesized by Masuda and co-workers using the azobenzene as a conjugative unit in the backbone [1, 8-10]. Polyamides containing azobenzene moieties in the main chain have also been synthesized [11] and they showed high $\mathrm{T}_{\mathrm{g}}$ $\left(>220{ }^{\circ} \mathrm{C}\right)$ and thermal stability under nitrogen $(\sim$ $400{ }^{\circ} \mathrm{C}$ ), with $50 \%$ char above $800{ }^{\circ} \mathrm{C}$ which were attributed to the participation of ether-group oxygen atoms in forming hydrogen bonds. Chen and co-workers have prepared flame-retardant-free and thermo-cross linkable epoxy resins containing azobenzene groups [12]. They observed that the enhanced flame retardance 
of the epoxy resins was due to the crosslinking reactions between the azobenzene groups which yield highly graphitized and flame-retardant material.

In this study, nine aromatic conjugated main-chain azobenzene polymers were synthesized and characterized by spectroscopy. Their thermal stability and degradation behavior were investigated and their likely use as flame-retardant additives was tested.

\section{Materials and Methods 2.1 Materials}

Starting compounds biphenyl, 4,4'-dinitrobiphenyl ether, 4-amino-4'nitro-biphenyl sulfide $\mathbf{3}$, triphenylamine $\mathbf{A}, \mathbf{N}$-methyl-diphenylamine $\mathbf{B}$ and triphenylphosphine $\mathbf{C}$ were purchased from SigmaAldrich. Solvents used and acids, hydrochloric acid 35 $\%$, sulfuric acid $98 \%$, nitric acid $70 \%$ and formic acid $90 \%$ were all analytical grade reagents and purchased from Sigma-Aldrich. Iron (III) chloride $\left(\mathrm{FeCl}_{3}\right)$, activated charcoal, hydrazine monohydrate $\left(\mathrm{N}_{2} \mathrm{H}_{4}\right)$, potassium carbonate $\left(\mathrm{K}_{2} \mathrm{CO}_{3}\right)$, sodium hydroxide $(\mathrm{NaOH})$, Zinc dust ( $\mathrm{Zn})$ were purchased from SigmaAldrich and used in their commercial forms.

\subsection{Experimental}

Syntheses were carried out in three steps, Figure 1. The first step is the selective reduction of dinitro compounds to nitro-amine derivatives. The second step is the azo group formation from nitro-amine compounds by the metal-catalyzed reduction of nitro groups, using $\mathrm{Zn}$ powder in aqueous hydroxide base. This step can be accepted as the preparation of diazo monomers. The last step is polymerization of diamino azobenzene monomers with comonomers, triphenylamine $\mathbf{A}, \mathrm{N}$ methyl-diphenylamine $\mathbf{B}$ and triphenylphosphine $\mathbf{C}$. The method used is a traditional method based on the treatment of aromatic amines with nitrous acid and then with an activated aromatic ring. The resultant nine polymers and three azobenzene monomers were characterized via ${ }^{1} \mathrm{H}-\mathrm{NMR}$, FTIR, Raman, and TGA techniques.

\subsubsection{Synthesis of Nitro Amine Derivatives by Selective Reduction}

Syntheses were performed according to the literature [13]. Nitroamine products 4-amino-4'-nitro biphenyl 1, 4-amino-4'-nitro-biphenyl ether 2 were obtained. 4amino-4'-nitro-biphenyl sulfide 3 was purchased.

\subsubsection{Synthesis of Azo Monomers}

Syntheses of 4,4'-bis(p-aminophenyl)azobenzene $\mathbf{1 m}$, $4,4^{\prime}$-bis ( $p$-aminophenoxy)- azobenzene $\mathbf{2 m}$ and 4,4' bis( $p$-aminophenylthio)azobenzene $\mathbf{3 m}$ were performed by the metal-catalyzed reduction of nitro groups using $\mathrm{Zn}$ powder in aqueous hydroxide base, according to the literature [14]. Final purification was carried out in trace water-free ethyl acetate to remove unreacted starting nitro amine compound.

1m: Orange solid. Yield $86 \%, \mathrm{~T}_{\mathrm{d}}: 267-269{ }^{\circ} \mathrm{C}$. FTIR $(\mathrm{KBr}), v\left(\mathrm{~cm}^{-1}\right): 3427-3338\left(\mathrm{NH}_{2}\right), 3213\left(\mathrm{NH}_{2}\right), 1593$, 1489, 1273, 821. UV-VIS, $\lambda_{\max }(\mathrm{nm}): 280,426 .{ }^{1} \mathrm{H}-$ NMR (400 MHz, DMSO d- $\left.{ }_{6}\right), \delta_{\mathrm{H}}(\mathrm{ppm}): 5.5(4 \mathrm{H} ; \mathrm{N}-\mathrm{H})$, 6.75 (4H; Ar-H), 7.6 (4H; Ar-H), 7.8 (4H; Ar-H), 8.3 (4H; Ar-H). RAMAN v $\left(\mathrm{cm}^{-1}\right)$ : 1138, 1239,1394, 1441($\mathrm{N}=\mathrm{N}-), 1589$.

2m: Dark green colored solid. Yield $65.6 \%, \mathrm{~T}_{\mathrm{d}}$ : 267$269{ }^{\circ} \mathrm{C}$. FTIR $(\mathrm{KBr}), \quad v \quad\left(\mathrm{~cm}^{-1}\right): 3398-3308\left(\mathrm{NH}_{2}\right)$, 3209 $\left(\mathrm{NH}_{2}\right)$, 1581, 1508, 1492, 1232, 1151, 840. UVVIS, $\lambda_{\max }(\mathrm{nm}): 362 .{ }^{1} \mathrm{H}-\mathrm{NMR}\left(400 \mathrm{MHz}, \mathrm{DMSO} \mathrm{d}_{-}\right.$), $\delta_{\mathrm{H}}(\mathrm{ppm}): 5.1(4 \mathrm{H} ; \mathrm{N}-\mathrm{H}), 6.6(4 \mathrm{H} ; \mathrm{Ar}-\mathrm{H}), 6.8(4 \mathrm{H} ; \mathrm{Ar}-$ $\mathrm{H}), 7.0(4 \mathrm{H} ; \mathrm{Ar}-\mathrm{H}), 7.8(4 \mathrm{H} ; \mathrm{Ar}-\mathrm{H})$, RAMAN $v\left(\mathrm{~cm}^{-1}\right)$ : $1288,1441(-\mathrm{N}=\mathrm{N}-), 1543$.

3m: Orange solid. Yield 83.3\%, $\mathrm{T}_{\mathrm{d}}: 267-269{ }^{\circ} \mathrm{C}$. FTIR $(\mathrm{KBr}), v\left(\mathrm{~cm}^{-1}\right): 3446-3340\left(\mathrm{NH}_{2}\right), 3217\left(\mathrm{NH}_{2}\right), 1631$, $1595,1577,1496,1303,1182,1078,829$. UV-VIS, $\lambda_{\max }$ (nm): 278, 396. ${ }^{1} \mathrm{H}-\mathrm{NMR}\left(400 \mathrm{MHz}\right.$, DMSO d-6), $\delta_{\mathrm{H}}$ (ppm): $5.6(4 \mathrm{H} ; \mathrm{N}-\mathrm{H}), 6.6(4 \mathrm{H} ; \mathrm{Ar}-\mathrm{H}), 7.1(4 \mathrm{H} ; \mathrm{Ar}-\mathrm{H})$, $7.2(4 \mathrm{H} ; \mathrm{Ar}-\mathrm{H}), 7.7\left(4 \mathrm{H} ;\right.$ Ar-H), RAMAN $v\left(\mathrm{~cm}^{-1}\right)$ : 1165, 1376, 1440(-N=N-), 1543.

\subsubsection{Polymerization by Diazo Coupling Reaction}

Synthesis of nine polymers was carried out by diazocoupling reaction. 0.005 moles of azobenzene monomer $1 \mathrm{~m}, \mathbf{2 m}, \mathbf{3 m}$ was dissolved in a homogenous mixture of $20 \mathrm{~mL}$ glacial acetic acid, $5 \mathrm{~mL}$ DMF and $1.4 \mathrm{~mL}$ sulfuric acid. Sodium nitrite $(0.015 \mathrm{~mol} / 0.9 \mathrm{~mL}$ water) was added dropwise into an acid solution at $0{ }^{\circ} \mathrm{C}$ to obtain diazonium salt. The mixture was stirred an additional one hour at $0{ }^{\circ} \mathrm{C}$. Diazonium salt was added dropwise into comonomer solution $(\mathbf{A}, \mathbf{B}, \mathbf{C})(0.0025$ moles in $40 \mathrm{~mL} \mathrm{DMF})$. After stirring 48 hours, the solution was poured into an excess of water and precipitate was filtered, washed and dried. The crude product was treated in hot DMF to remove low molecular weight and soluble materials. Dark brownblack powders were obtained. In order to purify the prepared materials, prepared dark brown-black powders were stirred in concentrated sulfuric acid for 2 hours at $40{ }^{\circ} \mathrm{C}$, and then the dark violet acid solution was reprecipitated in 1:5 DMF/water (v/v) and washed with plenty of ethyl alcohol. Shiny black solids were obtained as azo macromolecular products (1mA-C, 2mA-C and 3mA-C).

Polymer 1mA: FTIR (KBr), $v\left(\mathrm{~cm}^{-1}\right)$ : 3421, 3032, 1658, 1597, 1518, 1483, 1157, 1078, 1003, 831. UVVIS, $\lambda_{\max }(\mathrm{nm}): 284,392$. RAMAN, $v\left(\mathrm{~cm}^{-1}\right): 1135$, 1283, 1404(-N=N-), 1444(-N=N-), $1586 .{ }^{1} \mathrm{H}-\mathrm{NMR}$ study failed due to very low solubility. 
Polymer 2mA: FTIR (KBr), v $\left(\mathrm{cm}^{-1}\right)$ : 3448, 3064, 1585, 1487, 1384, 1332, 1238, 1080, 837. UV-VIS, $\lambda_{\max }$ (nm): 290, 348. ${ }^{1} \mathrm{H}-\mathrm{NMR}\left(400 \mathrm{MHz}\right.$, DMSO d- $\left.{ }_{6}\right), \delta_{\mathrm{H}}$ (ppm): 7-8.2 (Ar-H).

Polymer 3mA: FTIR (KBr), $v\left(\mathrm{~cm}^{-1}\right)$ : 3452, 3057, $1664,1577,1477,1450,1388,1078,827$. UV-VIS, $\lambda_{\max }$ (nm): $286,386 .{ }^{1} \mathrm{H}-\mathrm{NMR}$ study failed due to very low solubility.

Polymer 1mB: FTIR (KBr), $v\left(\mathrm{~cm}^{-1}\right): 3460,3030,2875$, 1664, 1591, 1124, 1111, 823. UV-VIS, $\lambda_{\max }(\mathrm{nm}): 286$, 372. ${ }^{1} \mathrm{H}-\mathrm{NMR}\left(400 \mathrm{MHz}, \mathrm{DMSO} \mathrm{d}_{-}\right.$), $\delta_{\mathrm{H}}(\mathrm{ppm}): 2.5-3$ (C-H); 7.5-8.5 (Ar-H).

Polymer 2mB: FTIR (KBr), v (cm $\left.{ }^{-1}\right)$ : 3059, 2874, 2816, 1587, 1492, 1348, 1236, 1145, 837. UV-VIS, $\lambda_{\max }(\mathrm{nm})$ : 280, 356, 456. ${ }^{1} \mathrm{H}-\mathrm{NMR}\left(400 \mathrm{MHz}, \mathrm{DMSO} \mathrm{d}_{-6}\right), \delta_{\mathrm{H}}$ (ppm): 2.5-3 (C-H); 6.9-8.2 (Ar-H).

Polymer 3mB: FTIR (KBr), $v\left(\mathrm{~cm}^{-1}\right)$ : 3056, 2927, 2810, $1585,1080,837$. UV-VIS, $\lambda_{\max }(\mathrm{nm}): 286,386,468 .{ }^{1} \mathrm{H}-$ NMR (400 MHz, DMSO d-6), $\delta_{\mathrm{H}}(\mathrm{ppm}): 2.5-3(\mathrm{C}-\mathrm{H})$; 6.9-8.2 (Ar-H)

Polymer 1mC: FTIR (KBr), $v\left(\mathrm{~cm}^{-1}\right)$ : 3439, 3028, 1593, 1454, 1383, 1334, 1166, 1082, 1001, 827. UV VIS, $\lambda_{\max }(\mathrm{nm}): 286,390 .{ }^{31} \mathrm{P}-\mathrm{NMR}$ (400 MHz, DMSO $\left.\mathrm{d}-{ }_{6}\right), \delta_{\mathrm{H}}(\mathrm{ppm}): 25$.

Polymer 2mC: FTIR (KBr), $v\left(\mathrm{~cm}^{-1}\right)$ : 3470, 3059, $1587,1533,1491,1238,1143,837$. UV-VIS, $\lambda_{\max }(\mathrm{nm})$ 288, 358. ${ }^{31} \mathrm{P}-\mathrm{NMR}\left(400 \mathrm{MHz}, \mathrm{DMSO} \mathrm{d}_{-}\right), \delta_{\mathrm{H}}(\mathrm{ppm})$ : 25.

Polymer 3mC: FTIR (KBr), $v\left(\mathrm{~cm}^{-1}\right)$ : 3057, 1674, 1583, 1492, 1078, 821. UV-VIS, $\lambda_{\max }(\mathrm{nm}): 286,386$. ${ }^{31} \mathrm{P}-\mathrm{NMR}$ (400 MHz, DMSO d-6), $\delta_{\mathrm{H}}$ (ppm): 25.

\subsubsection{Carbonization of the Azobenzene Polymers}

Carbonization was carried out in two stages using $1 \mathbf{m A}$, at $400{ }^{\circ} \mathrm{C}$ for an hour and then $800{ }^{\circ} \mathrm{C}$ for $2 \mathrm{hrs}$ in an oven under a nitrogen atmosphere, in order to evaluate the gradual thermal decomposition of the polymers.

\subsubsection{Characterization}

FT-IR spectra of the polymers and monomers were obtained in $\mathrm{KBr}$ disc using a Shimadzu FTIR Spectrometer in the range of $400-4000 \mathrm{~cm}^{-1}$ frequency. Raman spectra were recorded on Homemade Confocal RAMAN Setup installed at material instrumentation, with a He-Ne laser source of $633 \mathrm{~nm}$ line width and a power of $20 \mathrm{mV} .{ }^{1} \mathrm{H}-\mathrm{NMR}$ were recorded on Bruker $400 \mathrm{MHz}$ spectrometer in DMSO- $\mathrm{d}_{6} \cdot{ }^{31} \mathrm{P}-\mathrm{NMR}$ spectroscopy of polymers consisting of TPP was recorded with using Varian $600 \mathrm{MHz}$ in $\mathrm{DMSO}_{6}$ solution. UV spectra were recorded by JASCO V-530 UV-vis spectrophotometer using DMF as a solvent. The thermal stability of polymers was studied by thermogravimetric analysis (TGA) over a temperature range from 25 at $900{ }^{\circ} \mathrm{C}$ under a nitrogen atmosphere at heating rates $20{ }^{\circ} \mathrm{C} / \mathrm{min}$ using Perkin Elmer Pyris 1 model. X-ray diffraction (XRD) analysis of the carbonized polymers was obtained by a Rigaku Multiflex + XRD diffractometer with a monochromatic beam (wavelength of $1.54 \AA$ ) derived from a $\mathrm{CuK}_{\alpha}$ target. A scanning electron microscope (SEM, JEOL $6390-\mathrm{LV}$ ) with the accelerating voltage of $20 \mathrm{kV}$ was used to investigate the surface morphology and elemental composition of the carbonized polymers.

\section{Results and Discussion \\ 3.1 Characterization of the Polymers}

Prepared monomers and polymers (Figure 1) were characterized by ${ }^{1} \mathrm{H}$ - and ${ }^{31} \mathrm{P}-\mathrm{NMR}$, FTIR, UV-Vis and Raman spectroscopy. The most informative signals in the FTIR spectra of nitroamine derivatives $(\mathbf{1 m}, \mathbf{2 m}$, $3 m)$ are observed at $1585-1600 \mathrm{~cm}^{-1}$ and $1400-1500 \mathrm{~cm}^{-}$ ${ }^{1}$ (aromatic $\mathrm{C}=\mathrm{C}$ stretching), $1500-1550 \mathrm{~cm}^{-1}$ and 1360$1290 \mathrm{~cm}^{-1}$ (asymmetric and symmetric $\mathrm{NO}_{2}$ stretching), and near to $3500 \mathrm{~cm}^{-1}$ and $3400 \mathrm{~cm}^{-1}$ (asymmetric and symmetric N-H stretching). Furthermore, a strong band in the region of 1000-1260 $\mathrm{cm}^{-1}$ (asymmetric C-O-C stretching) in $\mathbf{2 m}$ and its derivatives and a weak band in the region of $600-700 \mathrm{~cm}^{-1}$ (C-S-C stretching) in $3 \mathbf{m}$ and its derivatives were also observed. To compare, the representative FTIR spectra of $\mathbf{1} \mathbf{m}$ and its corresponding molecules, are given in Figure 2. The bands at $3385 \mathrm{~cm}^{-}$ 1 and $3489 \mathrm{~cm}^{-1}$ (symmetric and asymmetric N-H stretching, respectively), $1627 \mathrm{~cm}^{-1}$ (N-H bending), $1587 \mathrm{~cm}^{-1}-1496 \mathrm{~cm}^{-1}$ (aromatic $\mathrm{C}=\mathrm{C}, \quad \mathrm{C}-\mathrm{C}$ ring stretching), $1330 \mathrm{~cm}^{-1}$ (symmetric $\mathrm{N}-\mathrm{O}$ stretching), $1278-1207 \mathrm{~cm}^{-1}\left(\mathrm{C}_{\mathrm{sp}}{ }^{2}-\mathrm{N}\right.$ stretching), $1112 \mathrm{~cm}^{-1}$ (in-plane $\mathrm{C}-\mathrm{H}$ bending), $825 \mathrm{~cm}^{-1}$ (out of plane $\mathrm{C}-\mathrm{H}$ bending) suggest the presence of compound 1. In the FTIR spectrum of $\mathbf{1 m}$, the formation of the azo group can be confirmed by the disappearance of the N-O stretching. The azobenzene polymers showed the characteristic peaks of its corresponding monomers, at $1587 \mathrm{~cm}^{-1}$ $1496 \mathrm{~cm}^{-1}$ (aromatic $\mathrm{C}=\mathrm{C}, \mathrm{C}-\mathrm{C}$ ring stretching), 1278$1207 \mathrm{~cm}^{-1}\left(\mathrm{C}_{\mathrm{sp}}{ }^{2}-\mathrm{N}\right.$ stretching), $1112 \mathrm{~cm}^{-1}$ (in-plane $\mathrm{C}-\mathrm{H}$ bending), $825 \mathrm{~cm}^{-1}$ (out of plane $\mathrm{C}-\mathrm{H}$ bending) as well as $1000-1260 \mathrm{~cm}^{-1}$ (asymmetric C-O-C stretching) for 2mA, 2mB, 2mC and 600-700 $\mathrm{cm}^{-1}$ (C-S-C stretching) for $\mathbf{3 m A}, 3 \mathbf{m B}, 3 \mathbf{m C}$ except the amino bands whose intensities decreased with the increase of azo group content in polymerization and so the spectra of polymers resemble each other since the only difference is the spacer atoms, N, S and P (see ESI Figure S1 and S2). The $-\mathrm{N}=\mathrm{N}$ - group peaks were not observed in the infrared spectra probably due to relatively symmetric nature of azo monomers. 


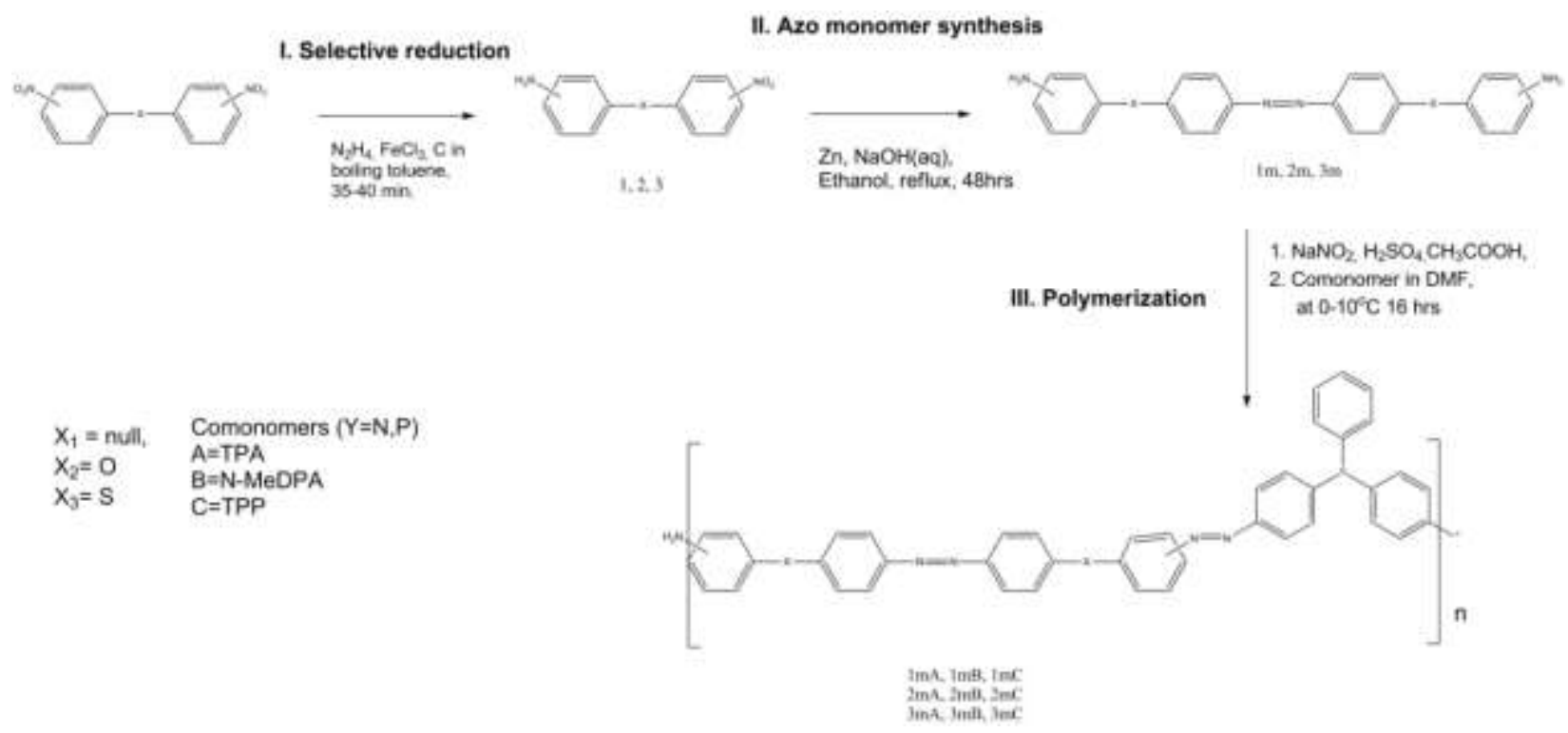

Figure 1. Synthesis procedure for the conjugated main chain azo polymers

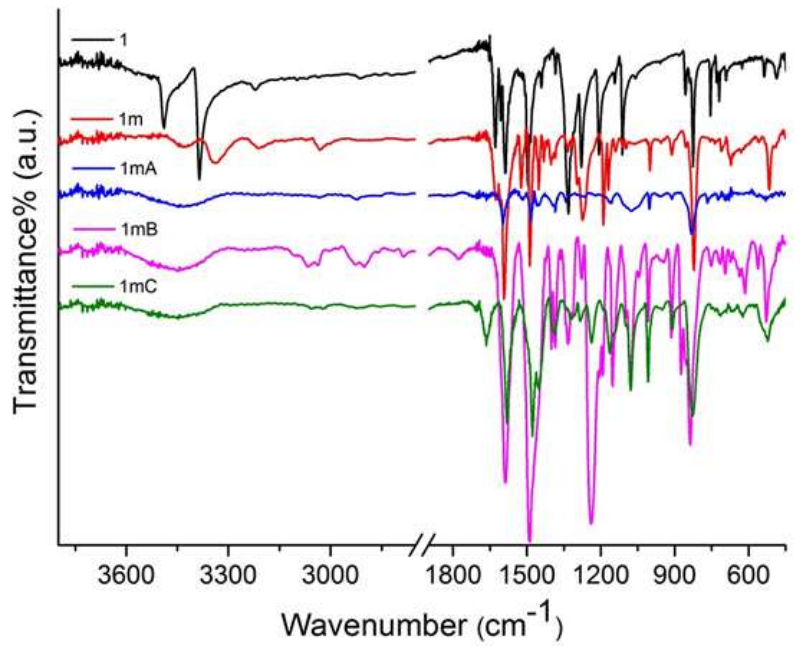

Figure 2. FTIR spectra of $1,1 \mathrm{~m}, 1 \mathrm{~mA}, 1 \mathrm{mB}$ and $1 \mathrm{mC}$.

Azo group formation was further probed by using Raman spectroscopy. Raman stretching of $-\mathrm{N}=\mathrm{N}$ - was observed at around $1441 \mathrm{~cm}^{-1}$ for monomers $1 \mathbf{m}, \mathbf{2 m}$, 3m (Please see typical Raman spectra of $1 \mathbf{m}$ and $1 \mathbf{m A}$ in ESI Figure S3). Polymers give aromatic $-\mathrm{N}=\mathrm{N}$ stretching at $1441 \mathrm{~cm}^{-1}$ and at $1444 \mathrm{~cm}^{-1}$. Most azo $\mathrm{N}=\mathrm{N}$ stretching bands occur between $1580 \mathrm{~cm}^{-1}$ and $1400 \mathrm{~cm}^{-}$ ${ }^{1}$ in the Raman spectrum [15]. These peaks may be due to the two azo groups with different chemical environments.
${ }^{1} \mathrm{H}-\mathrm{NMR}$ analysis of the polymers synthesized by the co-monomers $\mathbf{B}$ and $\mathbf{C}$ was challenging due to their low solubility in common NMR solvents, although the polymers with $\mathbf{B}$ showed better solubility in hot acetone, hot xylene and hot 1,2-dichlorobenzene, likely because of their linearity in the chain. Thus, we were only able to make a detailed ${ }^{1} \mathrm{H}-\mathrm{NMR}$ analysis of $\mathbf{2 m A}$. A typical ${ }^{1} \mathrm{H}$-NMR spectrum of the monomer (2mA) is given in Figure 3. (see ESI Figure S4-10 for additional ${ }^{1} \mathrm{H}$ NMR spectra of the monomers and their corresponding polymers) The peaks around $6.5-8.5 \mathrm{ppm}$ are related to the aromatic hydrogens and the peak with very low intensity appearing at $5-5.5 \mathrm{ppm}$ is attributed to the amine hydrogens. An increase in the intensity of $\mathrm{H}_{\mathrm{a}}, \mathrm{H}_{\mathrm{b}}$, $\mathrm{H}_{\mathrm{c}}$ and $\mathrm{H}_{\mathrm{d}}$ was attributed to polymerization of $2 \mathbf{m}$ with A because of the increase in the chain length. Furthermore, the peak at $5.1 \mathrm{ppm}$ corresponds to the protons of the amino groups $\left(\mathrm{H}_{\mathrm{e}}\right)$ was disappeared in the ${ }^{1} \mathrm{H}-\mathrm{NMR}$ spectrum of $\mathbf{3 m}$ after the polymerization reaction evidencing the polymerization. Chemical shift ranges of $\mathrm{PPH}_{3}$ compounds were referenced to $0-10$ ppm. ${ }^{31}$ P-NMR spectroscopy of TPP polymers $\mathbf{1 m C}$, $2 \mathrm{mC}$ and $\mathbf{3 m C}$ showed a chemical shift of phosphorus at 25 ppm (see ESI Figure S11-13). Furthermore, all monomers were soluble in common solvents and their polymers were slightly soluble in DMF, DMAc, DMSO and pyridine at room temperature. However, prepared polymers were soluble in DMF and DMSO at $100{ }^{\circ} \mathrm{C}$ and concentrated $\mathrm{H}_{2} \mathrm{SO}_{4}$ at $50{ }^{\circ} \mathrm{C}$. 


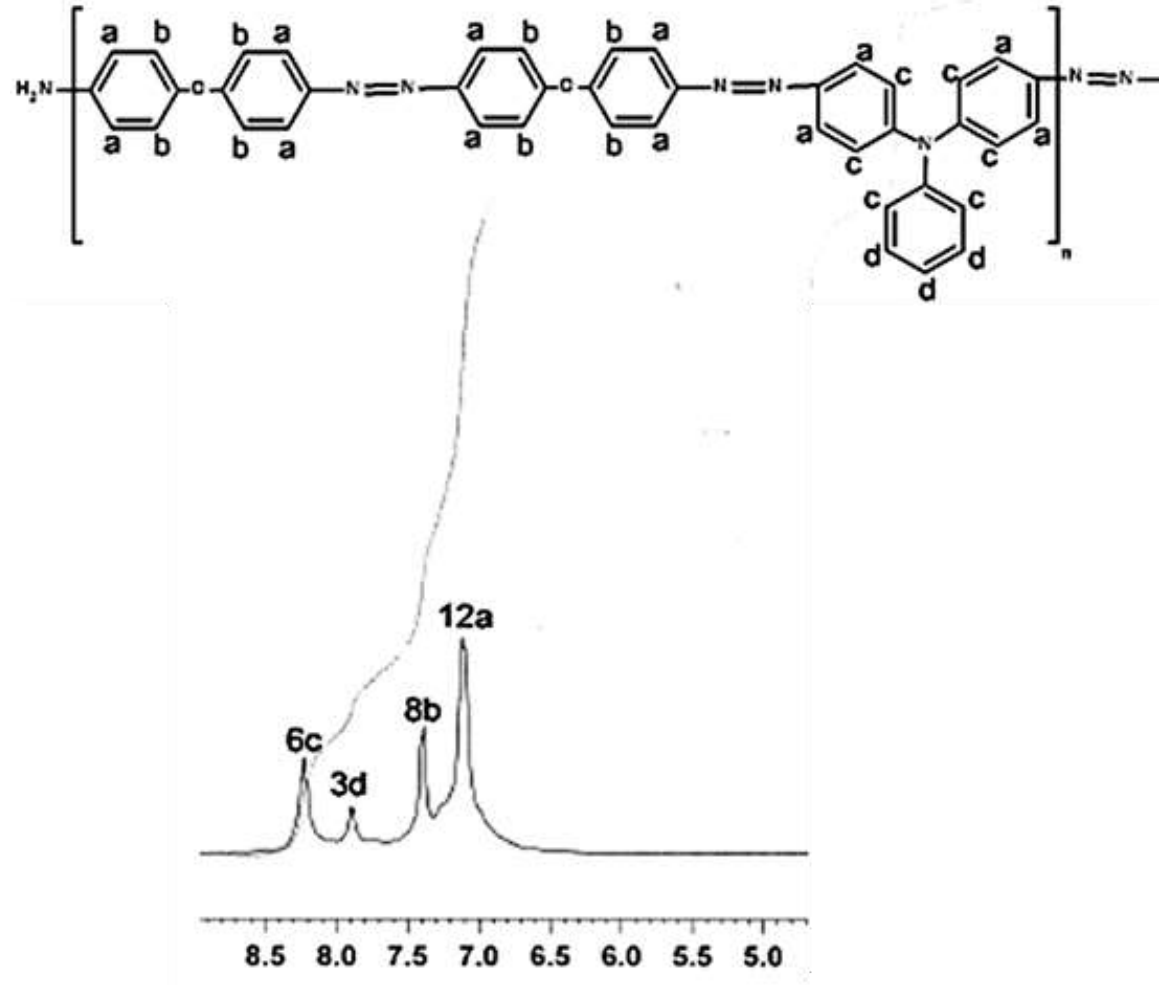

Figure 3. ${ }^{1} \mathrm{H}-\mathrm{NMR}$ Spectrum of $\mathbf{2} \mathbf{m A}$.

\subsection{Optical Properties of the Polymers}

Representative UV-Vis spectra of azo molecules $\mathbf{2}, \mathbf{2 m}$ and $\mathbf{2 m A}$ are shown in ESI Figure S14 and the observed absorption peaks are given in Table 1. The peak observed at around $280-300 \mathrm{~nm}$ due to the benzenoid band, that is the characteristic of aromatic molecules $\pi \longrightarrow \pi^{*}$ transition. The maximum wavelength of $\mathbf{1}$ is observed at $400 \mathrm{~nm}$ which is the longest wavelength among aromatic nitro amine derivatives that the molecule have no spacer to destroy conjugation. Molecules with spacer like $\mathbf{2}$ and $\mathbf{3}$, were showed maximum absorption at shorter wavelengths, $308 \mathrm{~nm}$ and $346 \mathrm{~nm}$, respectively. The characteristic absorption peak of azo-aromatic chromophores of $\mathbf{1 m}, \mathbf{2 m}$ and $\mathbf{3 m}$ were observed at approximately 382, 362 and $348 \mathrm{~nm}$. All azo monomers were shifted either longer or shorter wavelength compared to those of the starting amino nitro derivatives. The UV-Vis spectra of polymers qualitatively independent of the length of the flexible segment along the chain and only depend on the active azo containing units. Their absorption maxima shift slightly to shorter wavelength, compared with monomers $\mathbf{1 m}, \mathbf{2 m}$ and $\mathbf{3 m}$ likely due to increasing conjugation. Overall UV-Vis results suggest that any change in spacer atom may alter the absorption maximum of the macromolecule.
Table 1. Wavelength maxima and the expected electronic transitions of the monomers $(\mathbf{1 m}, \mathbf{2 m}$ and 3m) and their corresponding polymers in DMF.

\begin{tabular}{|c|c|c|c|}
\hline & $\begin{array}{c}\text { Max. } \\
\text { Absorption }\end{array}$ & & \\
\hline Product & $\begin{array}{c}\pi \longrightarrow>\pi^{*} \\
\text { (Benzenoid } \\
\text { Band) }\end{array}$ & $\begin{array}{c}\pi \longrightarrow \pi^{*} \\
\text { (Conjugation) }\end{array}$ & $\mathrm{n} \longrightarrow>\pi^{*}$ \\
\hline $1 \mathrm{~m}$ & 280 & 426 & - \\
\hline $2 m$ & - & 362 & - \\
\hline $3 \mathrm{~m}$ & 278 & 396 & - \\
\hline $1 \mathrm{~mA}$ & 284 & 392 & - \\
\hline $2 \mathrm{~mA}$ & 290 & 348 & - \\
\hline $3 \mathrm{~mA}$ & 286 & 386 & - \\
\hline $1 \mathrm{mB}$ & 286 & 372 & - \\
\hline $2 \mathrm{mB}$ & 280 & 356 & 456 \\
\hline $3 \mathrm{mB}$ & 286 & 386 & 468 \\
\hline $1 \mathrm{mC}$ & 286 & 390 & - \\
\hline $2 \mathrm{mC}$ & 288 & 358 & - \\
\hline $3 \mathrm{mC}$ & 286 & 386 & - \\
\hline
\end{tabular}


Celal Bayar University Journal of Science

Volume 15, Issue 4, 2019 p 329-336

Doi: $10.18466 /$ cbayarfbe. 446974

Ö.Özdemir

\subsection{Thermal and Degradation Properties of the Polymers}

It is known that azobenzene groups commonly start to decompose at around $300{ }^{\circ} \mathrm{C}$ through nitrogen elimination $[10,16,17]$. This depends on the varying strength of $\mathrm{N}=\mathrm{N}$ bond in the conjugation. Typical thermogram of $1 \mathbf{m A}$ is given in Figure 4.

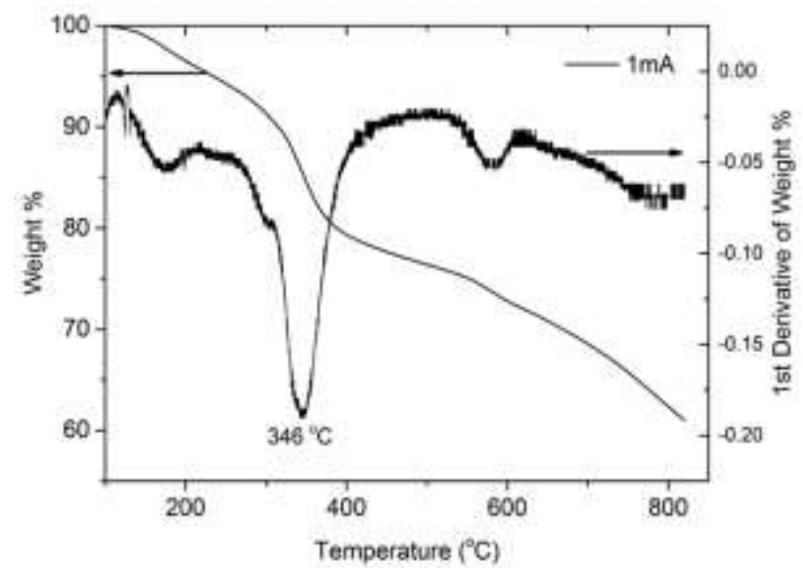

Figure 4. TGA thermogram of 1mA under an $\mathrm{Ar}$ atmosphere and its first derivative.

The onset of $20 \%$ and $40 \%$ weight loss and char yields at $900{ }^{\circ} \mathrm{C}$ for all prepared polymer samples are also given Table 2 . As expected polymers do not have so high thermal stability due to the low decomposition temperature of the azo bonds. Extrusion of molecular nitrogen facilitates the easy decomposition of polymers. Two different exothermic peaks in smaller intensity were observed at lower temperatures around 320 and $540-550{ }^{\circ} \mathrm{C}$ in a combination of all of the azobenzene polymers. The first weight-loss between $270{ }^{\circ} \mathrm{C}$ and 370 ${ }^{\circ} \mathrm{C}$ is attributed to the thermal degradation of azobenzene moieties, and the second weight-loss above $370{ }^{\circ} \mathrm{C}$ represents the thermal decomposition of the main chains. The thermal decomposition of the azobenzene polymers is matched closely with the literature $[12,15,16,18]$. The glass transition temperature $\left(\mathrm{T}_{\mathrm{g}}\right)$ was not detected likely because of the low molecular weight of the synthesized polymers. The melting point could not be determined for monomers $\mathbf{1 m}, \mathbf{2 m}, \mathbf{3 m}$, and their corresponding polymers due to the decomposition of azo moieties before melting temperature.

To further understand the carbonization process we subjected $1 \mathrm{~mA}$ to heat at $400{ }^{\circ} \mathrm{C}$ and $800{ }^{\circ} \mathrm{C}$ under a nitrogen atmosphere. In aggrement with FTIR analysis of as-prepared $1 \mathbf{m A}$, FTIR spectrum of $1 \mathbf{m A}$ heated at $400{ }^{\circ} \mathrm{C}$ displayed stretching frequencies at around 1610 , 1518,1175 and $827 \mathrm{~cm}^{-1}$ which were attributed to partial decomposition of the polyaromatic polymer structure. (see ESI Figure S15)

Table 2. Thermal \& thermooxidative stabilities of the monomers (1m, $\mathbf{2 m}$ and $\mathbf{3 m})$ and their corresponding polymers. *Decomposition start, confirmed by TGA under an Ar atmosphere.

\begin{tabular}{|c|ccc|c|c|c|}
\hline Product & \multicolumn{3}{|c|}{$\mathrm{T}_{\mathrm{d}}\left({ }^{\circ} \mathrm{C}\right)$} & $\begin{array}{c}20 \% \\
\text { Weight loss }\left({ }^{\circ} \mathrm{C}\right)\end{array}$ & $\begin{array}{c}40 \% \\
\text { Weight loss }\left({ }^{\circ} \mathrm{C}\right)\end{array}$ & $\begin{array}{c}\text { Residue }(\%) \\
\text { at } 900^{\circ} \mathrm{C}\end{array}$ \\
\hline $\mathbf{1 m}$ & 267 & 355 & 395 & - & - & 44.4 \\
\hline $\mathbf{2 m}$ & 269 & 365 & 418 & - & - & 30.8 \\
\hline $\mathbf{3 m}$ & 266 & 348 & 415 & - & $>800$ & 34.5 \\
\hline $\mathbf{1 m A}$ & 265 & & & 410 & 704 & 61.1 \\
\hline $\mathbf{2 m A}$ & 263 & & 455 & 710 & 50.3 \\
\hline $\mathbf{3 m A}$ & 254 & & 435 & 686 & 49.1 \\
\hline $\mathbf{1 m B}$ & 285 & & 455 & 670 & 46.4 \\
\hline $\mathbf{2 m B}$ & 277 & & 464 & 690 & 40.8 \\
\hline $\mathbf{3 m B}$ & 248 & & 437 & 694 & 54.8 \\
\hline $\mathbf{1 m C}$ & 274 & & 442 & 680 & 47.0 \\
\hline $\mathbf{2 m C}$ & 258 & & 445 & 680 & 48.0 \\
\hline $\mathbf{3 m C}$ & 252 & & & & -9 \\
\hline
\end{tabular}


In contrast, no IR signals were detected in the spectrum of $1 \mathbf{m A}$ carbonized at $800{ }^{\circ} \mathrm{C}$, suggesting complete carbonization of the polymer structure. This was not surprising since these aromatic systems bearing potentially reactive heteroatoms (e.g. nitrogen) could ease the graphitization of aromatic main chain azo polymers like in the case of the graphene quantum dots (GQDs) produced via assembly of large aromatic molecules by connecting or fusing them to nanometerscale carbon structures in some appropriate way such as "bottom up" approach [12, 19] Furthermore 1mA yielded $\sim 61 \%$ char at $800{ }^{\circ} \mathrm{C}$ probably following a crosslinking via aromatization processes of azobenzene, suggested by Chen and coworkers [12]. Formed carbon material was characterized by SEM/EDX and XRD, SEM image together with EDX data revealed the formation of highly stacked layered material consisting of 87.2\% carbon (Figure 5).

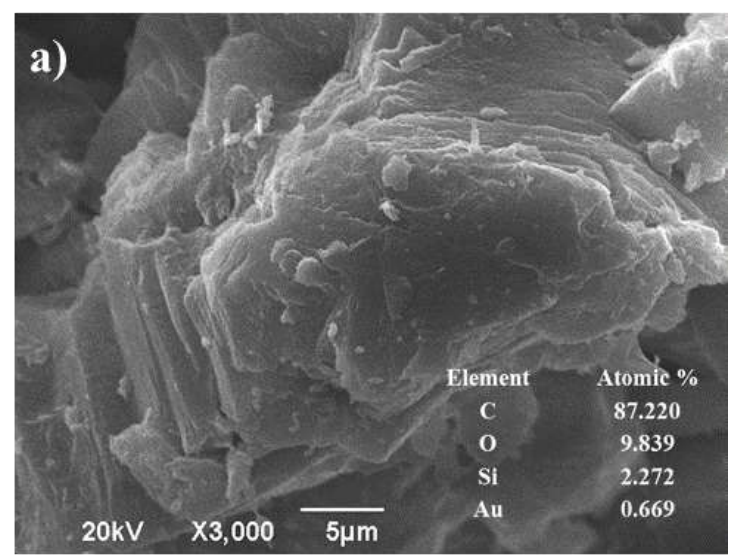

b)

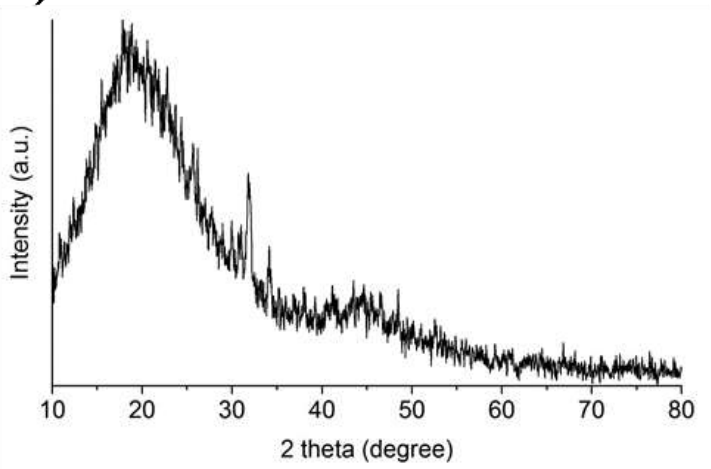

Figure 5. a) SEM image of the carbon material formed by heating $1 \mathrm{~mA}$ at $800{ }^{\circ} \mathrm{C}$ under a nitrogen atmosphere. Inset shows the elemental composition of the material identified by EDX. b) XRD diffractogram of the formed carbon material.

Surprisingly, no nitrogen was detected by EDX, suggesting complete removal of nitrogen moieties at $800{ }^{\circ} \mathrm{C}$ (Figure 5a). Complementary XRD further confirmed the formation of carbon nanosheet formation, showing two broad peaks at ca. 21 and $45^{\circ}$, characteristic of amorphous carbon nanostructures
(Figure 5b). Besides, two sharp XRD peaks at ca. 32 and $34^{\circ}$ were observed, however, they could not been identified.

\subsection{Flame Retardancy of the conjugated main- chain azobenzene polymers}

Polymers yielding high chars after subjecting to elevated temperatures can be utilized as flame retardant additives [20]. Thus we have investigated the flame retardancy property of the azobenzene polymer $1 \mathbf{m A}$. The effect of azo polymers on burning behavior of TPU Ravathane ${ }^{\circledR}$ (TPE-U) was examined following UL 94 flammability test. In a typical procedure TPU sample was mixed with varying amounts of $1 \mathbf{m A}$. Slight gas evolution followed by self-extinguishing was characteristic for all tested composite structures. Test results, which showed improved flame retardancy of the TPU samples, are given in Table 3.

Table 3. Flaming characteristics of $1 \mathrm{~mA}$ added TPU samples $(\mathrm{Yes}=\mathrm{Y}, \mathrm{No}=\mathrm{N})$.

\begin{tabular}{|l|c|c|c|c|c|}
\hline $\begin{array}{l}\text { 1mA (weight\% in } \\
\text { sample) }\end{array}$ & $\mathbf{0 . 0}$ & $\mathbf{0 . 0 1}$ & $\mathbf{0 . 1}$ & $\mathbf{1 . 0}$ & $\mathbf{1 . 5}$ \\
\hline $\begin{array}{l}\text { After flame or } \\
\text { afterglow of any } \\
\text { specimen up to } \\
\text { the 125mm mark }\end{array}$ & $\mathrm{N}$ & $\mathrm{N}$ & $\mathrm{N}$ & $\mathrm{N}$ & $\mathrm{N}$ \\
\hline $\begin{array}{l}\text { Cotton indicator } \\
\text { ignited by flaming } \\
\text { particles or drops }\end{array}$ & $\mathrm{Y}$ & $\mathrm{Y}$ & $\mathrm{Y}$ & $\mathrm{N}$ & $\mathrm{N}$ \\
\hline UL94 rating & $\mathrm{V}-2$ & $\mathrm{~V}-2$ & $\mathrm{~V}-2$ & $\mathrm{~V}-1$ & $\mathrm{~V}-0$ \\
\hline
\end{tabular}

\section{Conclusion}

In this study nine different main chain azobenzene polymers were synthesized from three monomers and three co-monomers. Our reaction conditions usually yielded low molecular weight polymers which are probably due to the low nucleophilic reactivity of aromatic co-monomers and the low solubility of the insitu formed pre-polymers. Raman spectroscopy analysis and thermal analyses (TGA) were confirmed the existence of two nonequivalent azo groups on polymer chains. The processibility of polymers in organic solvents was limited due to their low solubility. However, the azobenzene polymers can readily be carbonized into highly flame-resistant carbon nanosheet-like materials. This makes conjugated main chain azobenzene polymers interesting candidate as an intumescent fire retardant-reinforcing material in industrial applications, exploited here, to improve the flame retardancy of TPU Ravathane ${ }^{\circledR}$. 


\section{Acknowledgement}

This work has been supported by Abant Izzet Baysal University (Scientific Research Fund, BAP 2011 03-03393). The authors kindly acknowledge technical assistance of technical staff at TUBITAK-MAM, Chemistry Institute.

\section{Ethics}

There are no ethical issues after the publication of this manuscript.

\section{References}

1. Angiolini L, Smart Light-Responsive Materials: AzobenzeneContaining Polymers and Liquid Crystals. Macromolecular Chemistry and Physics, 2010, 211, 481.

2. Balasubramanian S, Kim J, Kim DY, Kumar J, Tripathy SK, Water soluble, conjugated main chain azo polymer: Synthesis and characterization. Macromolecular Rapid Communications, 1996, 17, 853-7.

3. $\mathrm{Wu} \mathrm{YL}$, Natansohn A, Rochon $\mathrm{P}$, Photoinduced birefringence and surface relief gratings in novel polyurethanes with azobenzene groups in the main chain. Macromolecules, 2001, 34, 7822-8.

4. Acierno D, Amendola E, Bugatti V, Concilio S, Giorgini L, Iannelli P, Synthesis and characterization of segmented liquid crystalline polymers with the azo group in the main chain. Macromolecules, 2004, 37, 6418-23.

5. Papagiannouli I, Iliopoulos K, Gindre D, Sahraoui B, Krupka O, Smokal V, Third-order nonlinear optical response of push-pull azobenzene polymers. Chemical Physics Letters, 2012, 554, 107-12.

6. Faghihi K, Hagibeygi M, New aromatic polyamide with Azo and phosphine oxide groups in the main chain. Turkish Journal of Chemistry, 2007, 31, 65-73.

7. Timpu D, Barboiu V, Airinei A, Rusu E, Transparent layers of azo-conjugated polymers: Preparation and opto-electrical properties. Journal of Optoelectronics and Advanced Materials, 2000, 2, 531-5.

8. Izumi A, Nomura R, Masuda T, Design and synthesis of stimuliresponsive conjugated polymers having azobenzene units in the main chain. Macromolecules, 2001, 34, 4342-7.

9. Izumi A, Teraguchi M, Nomura R, Masuda T, Synthesis of poly(p-phenylene)-based photoresponsive conjugated polymers having azobenzene units in the main chain. Macromolecules, 2000, $33,5347-52$

10. Izumi A, Teraguchi M, Nomura R, Masuda $T$, Synthesis of conjugated polymers with azobenzene moieties in the main chain. Journal of Polymer Science Part a-Polymer Chemistry, 2000, 38, 1057-63.

11. Yao JL, You YJ, Lei YA, Dong LJ, Xiong CX, Sun ZG, Mainchain azo polyaramides with high thermal stability and liquid crystal properties. Journal of Polymer Research, 2009, 16, 455-60.

12. Liu BW, Zhao HB, Tan $Y$, Chen L, Wang YZ, Novel crosslinkable epoxy resins containing phenylacetylene and azobenzene groups: From thermal crosslinking to flame retardance. Polymer Degradation and Stability, 2015, 122, 66-76.

13. Ozarslan O, Yilmaz T, Yildiz E, Fiedeldei U, Kuyulu A, Gungor A, The preparation of perfectly alternating poly(amide-imide)s via amide unit containing new diamine. Journal of Polymer Science Part a-Polymer Chemistry, 1997, 35, 1149-55.

14. Bigelow HE, Robinson DB, Azobenzene. Organic Syntheses, $1942,22,28-9$.

15. Georgi U, Reichenbach P, Oertel U, Eng LM, Voit B, Synthesis of azobenzene-containing polymers and investigation of their substituent-dependent isomerisation behaviour. Reactive \& Functional Polymers, 2012, 72, 242-51.

16. Nuyken $O$, Scherer $C$, Baindl $A$, Brenner AR, Dahn U, Gartner R et al., Azo-group-containing polymers for use in communications technologies. Progress in Polymer Science, 1997, 22, 93-183.

17. Jiang XY, Chen XB, Yue XG, Zhang JJ, Guan SW, Zhang HB, et al., Synthesis and characterization of photoactive poly(arylene ether sulfone)s containing azobenzene moieties in their main chains. Reactive \& Functional Polymers, 2010, 70, 616-21.

18. Pawelec W, Aubert M, Pfaendner R, Hoppe H, Wilen CE, Triazene compounds as a novel and effective class of flame retardants for polypropylene. Polymer Degradation and Stability, 2012, 97, 94854.

19. Bayazit MK, Moniz SJA, Coleman KS, Gram-scale production of nitrogen doped graphene using a 1,3-dipolar organic precursor and its utilisation as a stable, metal free oxygen evolution reaction catalyst. Chemical Communications, 2017, 53, 7748-51.

20. Ozarslan O, Bayazit MK, Catiker E, Preparation and Properties of Flame Retardant Poly(urethane-imide)s Containing Phosphine Oxide Moiety. Journal of Applied Polymer Science, 2009, 114, 1329-38. 